\title{
La labor hermenéutica de la Corte Internacional de Justicia en el fallo del diferendo territorial y marítimo entre Nicaragua y Colombia
}

\author{
Legal interpretation by the ICJ in the territorial and \\ maritime dispute between Nicaragua and Colombia
}

\author{
Alexander Cruz Martínez*
}

\section{Resumen}

A raíz de la sentencia dictada por la Corte Internacional de Justicia en 2012 en la demanda impetrada por Nicaragua contra Colombia, el presente artículo de reflexión académica explica la manera en que ese tribunal aplicó los diferentes métodos de hermenéutica jurídica, principalmente de corte finalista y subjetivistas, que tienen como punto de partida, el tratamiento que se da a sus fuentes. Esa forma de razonar es clave los Estados deciden llevar sus diferencias ante un juez internacional puesto que los posibles escenarios en que se resolverán los casos tienen una lógica propia y no pueden ser evaluados a luz del derecho interno. Palabras Clave: hermenéutica jurídica, rol del juez internacional, fuentes del derecho internacional, Corte Internacional de Justicia, diferendo colombo-nicaragüense.

\section{Abstract}

Based on the International Court of Justice's 2012 judgment concerning the application filed by Nicaragua against Colombia, this article explains how this court applied various methods of legal interpretation that treat

Director del departamento de derecho público de la Universidad Jorge Tadeo de Bogotá Colombia.<alexandercruzmartinez@hotmail.com>.

Recibido el 23 de septiembre de 2013; aceptado el 18 de junio de 2014. 
legal sources differently., These forms of interpretation are essential when states decide to take their disputes to an international tribunal since the various ways these cases can be resolved have their own logic and they cannot be evaluated according to domestic law principles.

KEYwords: legal interpretation, role of the international judge, sources of international law,International Court of Justice, dispute between Colombia and Nicaragua 


\section{INTRODUCCIÓN}

El 19 de noviembre de 2012 la Corte Internacional de Justicia (CIJ) ${ }^{1}$, dictó sentencia en la demanda presentada en 2001 por la República de Nicaragua contra el Estado de Colombia respecto de «un grupo de asuntos de orden jurídico pendientes» entre ambas naciones relacionados con el título de algunos territorios y la delimitación marítima en el Caribe Occidental. En ese contexto, el presente artículo de reflexión académica tiene como propósito revisar los métodos y directrices de interpretación utilizados en esa oportunidad por el tribunal.

El análisis parte del supuesto de que la CIJ no aplicó una directriz o método único, sino que en razón de la naturaleza especial de las fuentes del derecho internacional y su ordenación no jerárquica, utilizó una serie de aproximaciones hermenéuticas, que sugieren diferentes escenarios de razonamiento y la posibilidad de soluciones diferen-

La CIJ es uno de los seis órganos principales del Sistema de las Naciones Unidas establecido en 1946. De acuerdo con su estatuto, la CIJ cumple funciones consultivas, mediante las cuales emite dictámenes, y dicta sentencias que ponen fin a controversias sometidas a su conocimiento por los Estados partes. En este contexto Nicaragua presentó su demanda el 6 de diciembre de 2001, conforme al estatuto y a lo previsto en el Tratado Interamericano de Soluciones Pacíficas, también conocido como «Pacto de Bogotá» firmado por ambos Estados el 30 de abril de 1948. Once años después el proceso judicial culminó con una sentencia definitiva. tes que también podrían calificarse de equitativas y por ende cobijadas por el derecho.

No se pretende, a partir del asunto sub examine, hacer una generalización sobre la forma en que actúa generalmente la CIJ, fenómeno que ha sido estudiado por autores como Torres, Treves y Valticós (1999) sino examinar el caso en sí. Al respecto, señala que la CIJ utilizó un método totalizante (Rabbi-Baldi, 2013: 357) al no seguir un método único en su labor hermenéutica ni circunscribirse a una fuente única. Para llevar a cabo esta tarea el artículo se dividió en cinco partes: en la primera hace un aproximación a la hermenéutica jurídica; en la segunda se plantea el papel del juez en el derecho internacional; en la tercera se analiza la tarea de la CIJ según las fuentes del derecho internacional; en la cuarta se reseña el fallo, y en la última se presentan las conclusiones.

\section{TIPOS DE INTERPRETACIÓN JURÍDICA}

Se entiende por hermenéutica la teoría científica del arte de interpretar textos o elementos (Dueñas, 2007: 49). En el campo del derecho se relaciona con la asignación de significado a expresiones del lenguaje jurídico a fin de darle vida al texto o determinar el sentido de una expresión dudosa. Por tanto, incluso en los casos fáciles y claros el juez siempre está interpretando. 
La doctrina alemana del siglo pasado, encabezada por Hans-Georg Gadamer, se encargó de estudiar el papel del juez y los distintos tipos de interpretación, encontrando que independientemente de la tradición jurídica o de los principios que rigen una rama del derecho en particular, se puede hablar de dos tipos de hermenéutica. En primera instancia se encuentra el método formalista, filológico, conservador o textual, que atiende la tradición original del positivismo. De otra parte, el método finalista, filosófico, progresista o contextual toma como base elementos extranormativos.

La aplicación de cada método depende de la rama del derecho deque se trate, de la jerarquía del juez o tribunal, de la ordenación de las fuentes y de la posibilidad de aplicar principios, valores o reglas en sentido dworkiano. También guarda relación con la posición del operador jurídico como productor o reproductor de las reglas de derecho. El primero tiene una gran libertad, llegando a convertirse momentáneamente en un órgano político, sin representación popular, que puede apartarse de lo predicho. En cambio el segundo, estaría necesariamente atado a lo predeterminado por un mandato externo.

Frente a la interpretación causalista, su origen se da como consecuencia directa de la pretensión de cientificidad del derecho acuñada por el positivismo jurídico, que estableció normas claras y universales sobre el funcionamiento del sistema legal que permitirían al operador jurídico erradicar aparentes disfuncionalidades del sistema, como antinomias y lagunas, mediante el uso de métodos lógicos, de tal manera de llegar siempre a una solución única que se caracterizada por ser justa.

Esta forma tradicional de entender la ciencia jurídica concordaba perfectamente con la tradición civilista continental europea de acuerdo con cual la Ley emanada del Parlamento, en representación de la nación, era el ideal de fuente principalísima del derecho. Por tanto, los jueces y la ley eran solo medios de los que se valía la justicia. Montesquieu concebía al juez como «bouche de la loi» y en ese sentido su labor se reduciría a aplicar la norma y no a interpretarla, ya que esto correspondía de manera privativa a su autor. Desde la compilación de Justiniano se impuso la máxima "Alias autem legum interpretationes, immo magis perversiones eos iactare non concedimus».

Con el paso del tiempo y dada la dificultad de acudir en cada caso a la instancia parlamentaria, el juez fue adquiriendo cierto margen de maniobra en la interpretación, limitado en todo caso al ámbito causalista, es decir, al tenor literal o al contexto en que se produjo, y a una serie de reglas que aparecen en los primeros códigos civiles con la pretensión de dar claridad a todo el sistema. Por ejemplo, en el caso colombiano, parte de ello se refleja en los capítulos iniciales del Código Civil, de tradición napoleónica, y en las disposiciones que aún subsisten de la leyes 57 de 1887 y 153 de 1887 
con la correspondiente modulación que ha hecho la Corte Constitucional colombiana en algunos de sus apartes (Sentencia C-461 de 2013).

Hoy en día esta forma de entender el derecho resulta problemática ya que lo cierra de tal manera que restringe la introducción de elementos externos, puesto que en la práctica sus inconsistencias son difíciles de resolver en su propio seno. Reconocer que el sistema es abierto y que necesita elementos externos no ha sido tarea fácil ya que las escuelas causalistas, especialmente la de la exégesis, le ha hecho frente a las tendencias finalistas que en esa labor han cambiado el orden tradicional de las fuentes y han hecho evolucionar el papel del juez hacia uno dinámico y pragmático en algunos campos específicos.

En cambio, el finalismo es realista, práctico y crítico. Incluso tiende a hacer análisis metajurídicos, como el económico, y permite el ingreso de principios y su ponderación. El formalismo está pegado a la palabra, escrita por un legislador que se reputa sabio e informado, y a la filología que lo ata en su labor mediante los ya conocidos tipos de interpretación exegética acuñados desde la Escuela histórica liderada por Savigny, como el gramatical, el lógico, el histórico y el sistemático.

Sin duda la tradición positivista con pretensión estabilizadora ha entrado en crisis y el sistema ha debido evolucionar buscando salidas. Poco a poco, el fenómeno globalizante ha permitido que ciertas ramas del derecho, especial- mente el internacional y el constitucional funcionen con una lógica abierta, al estilo anglosajón, de acuerdo con el cual las fuentes tienen un significado y una ordenación propios y diferente del derecho interno. Muchos tribunales, al considerárseles activistas, prescinden de las fuentes cuando ellas no se acomodan al fin perseguido y aplican la equidad basándose en criterios que se corresponden con la política interna y con cuestiones de geopolítica y mantenimiento de la paz y el orden mundiales.

Otro problema que se plantea en ese nuevo escenario es el de la solución única respecto de los casos difíciles. Dworkin señala que sí es posible y exige la toma de una decisión correcta ante la indeterminación del lenguaje, pues los jueces no resuelven basándose en sus corazonadas sino en reglas y principios aplicables al caso. En cambio, Hart admite varia soluciones correctas, lo que podría ser contrario al principio de legalidad y desconocer la existencia del Estado de derecho. En todo caso, el hecho de optar por una hermenéutica finalista exigiría definir el resultado y luego buscar los medios y justificaciones que lleven hacia ese escenario. En este caso hay mayor discrecionalidad, aunque esta siempre debe ser reglamentada.

En el caso colombiano, al juez constitucional se le ha reconocido ampliamente su labor hermenéutica activista y finalista, al entenderse la Constitución como una norma de superior rango, de contenido jurídico y político, que le dota de múltiples herramientas inter- 
pretativas para poder hacer efectivos los principios y valores en que ella se funda, los que son maleables frente a la evolución constante de los fenómenos y las realidades sociales. La ciudadanía está empezando a acostumbrarse a este tipo de fallos que aunque incorporan elementos novedosos, lo ubican en un terreno de incertidumbre, al desafiar el statu quo de un sistema que históricamente se ha basado en el causalismo.

Ejemplo de lo anterior es la aplicación directa de principios tales como el prohomine (Sentencia T-319/12) que en la interpretación de las normas jurídicas impone la que sea más favorable al hombre y sus derechos; el de proporcionalidad (Sentencia C-296/12); o el de protección del derecho, que exige la preservación de la ley, en defensa del principio democrático, cuando esta admite varias interpretaciones, retirando la lectura inconstitucional (Sentencia C-478/03).

Lo afirmado hasta aquí no significa que la hermenéutica causalista deba desaparecer o tienda a hacerlo. El profesor argentino Rabbi-Baldi (2013: 357) señala que los diferentes tipos de directrices hermenéuticas no se presentan de manera aislada sino que se aplican en forma conjunta, lo que denomina interpretación totalizante, en cuanto se emplean varias de ellas, buscando no solo dar cuenta del sentido de la norma sino también abrirse a la realidad del problema para hallar una decisión justa del caso. Como se verá más adelante, en la sentencia en estudio la CIJ utilizó este tipo de interpretación a partir de elementos intranormativos, como el gramatical, el histórico, y el teleológico, y extranormativos como el criterio de autoridad, la equidad, la valoración de las consecuencias, entre otros.

\section{EL PAPEL DEL JUEZ EN EL DERECHO INTERNACIONAL}

Grossman (2011:100) señala que el derecho internacional ha tenido momentos claves como la época de Langdell $^{2}$ en que la Corte Permanente de Justicia Internacional, antecesora de la CIJ, reflejaba en sus fallos el principio de soberanía nacional como absoluto. Se toma como paradigma el caso Lotus de 1927 en que se ratificó que los Estados pueden extender la aplicabilidad de las leyes a personas y actos cometidos en alta mar, puesto que lo que no está prohibido por el derecho internacional está permitido. Cada Estado se halla aislado y su dinámica se ajusta a sus necesidades locales sin ceder su soberanía. En Harvard, Langdell perfilaba la enseñanza del derecho como una ciencia endógena que contiene principios y reglas que se deducen de los casos a fin de dar orden, certeza y coherencia.

A raíz del fin de la segunda guerra mundial, los Estados se hacen conscientes de la necesidad de un nuevo orden global puesto que al no estar aislados y al comprometer en sus acciones la paz mundial, surge la necesidad de flexibi-

\footnotetext{
2 Christopher Columbus Langdell, decano de la Facultad de derecho de la Universidad de Harvard de 1870 a 1895.
} 
lizar el principio de autodeterminación a partir de la cesión de soberanía a organizaciones supranacionales que orientan ese nuevo orden. En 1969, con el fallo de la CIJ sobre la Plataforma Continental del Mar del Norte (República Federal Alemana/Dinamarca: República Federal Alemana/Países Bajos, 1969) se establece un nuevo paradigma al establecerse el principio de «obligación sin aceptación» de acuerdo con el cual la costumbre internacional general y las normas y obligaciones comunes deben tener efectos automáticos para todos los Estados; de tal forma que los ordenamientos jurídicos internos se edifiquen a partir del orden internacional. Una de las partes no había aceptado el tratado de 1958, de lo que se deducía que no era aplicable, pero no fue así.

Kantarowicz, citado por RabbiBaldi (2013: 299) señala que el derecho internacional o de gentes es

«aquella rama del derecho en que menos abunda la materia positiva... rama que todavía hoy, sobre todo fuera de Alemania, aparece más estrechamente unida a la filosofía del Derecho que cualquier otra».

El carácter enunciado respecto de la escasa participación del derecho positivo encuadrasen un finalismo racionalista que determina una ordenación de las fuentes diferente de la tradicionalmente conocida en los ordenamientos internos de procedencia europeo continental.

En ese sentido, la finalística propia del derecho internacional irradia la interpretación y uso de sus fuentes. De acuerdo con Pagliari (2004: 460) «la necesidad de adecuar permanentemente sus normas a la realidad social, atento a los cambios producidos en la comunidad internacional, produjo una ampliación de las funciones del derecho internacional que se centró básicamente en tres objetivos: la protección de los derechos humanos, la cooperación y el desarrollo, y la conservación del medio ambiente».

Al respecto, se justificaría que el juez internacional no se atuviera estrictamente a las normas estatuidas para resolver el caso sometido a su conocimiento. La propia naturaleza del derecho internacional hace que este imparta justicia con base en otro tipo de criterios o elementos jurídicos. Más que declarar, estaría constantemente creando derecho puesto que al no importarle el formalismo ni complacer al sistema, trabajaría mayoritariamente con el método inductivo, al estilo del Common Law.

Por lo anterior, de acuerdo con nuestra tradición jurídica los fallos de estos jueces pueden llegar a generar polémica. Nuestro sistema se cimienta en la primacía de la norma positiva establecida en la Constitución, en la Ley o en el acto administrativo. Excepcionalmente se admite el uso de la costumbre, la jurisprudencia, los principios generales de derecho, la equidad, o mecanismos como la analogía, bajo la premisa de que se trata de un sistema cerrado. Esa concepción tradicionalista se corresponde con un método de análisis causalista que los tribunales internacionales utilizarían solo si hubiese que escudriñar el tenor literal de lo escrito, o 
la intencionalidad del contexto propio en el que se produjo la norma.

Radbruch (1935), retomando la idea de August Boeckh, señala que el causalismo se corresponde con el «conocimiento de lo conocido" o «la meditación de lo ya pensado». Es hacer sobre lo hecho. Sin embargo, el derecho internacional obedece a una racionalidad diferente y a una lógica más flexible y realista en la que en ausencia de la ley o tratado, lo cual es frecuente, debe acudir a la jurisprudencia, la costumbre, la equidad y a otros elementos que hacen del juez un activista de avanzada frente al sistema. En muchos casos, el juez internacional tiene que decir lo que es el derecho en ausencia de norma escrita, por lo que debe hacer uso del case-law, que privilegia las reglas jurisprudenciales.

Por ende, en el procedimiento interpretativo concurren diferentes elementos para hacer plausible los cometidos del derecho, lo que podría identificarse con una hermenéutica totalizante. Lo anterior, sin desconocer que la CIJ, al igual que cualquier juez colegiado, debe dictar una solución consensuada en su interior por la mayoría, lo cual no ocurre de manera espontánea, es decir que prima el consenso y no la opinión mejor sustentada. En el presente caso, siete jueces se pronunciaron separadamente para disidir o aclarar cuestiones relativas al fallo.

Entender que así funciona la justicia internacional es fundamental para que los gobiernos y los tomadores de decisiones en el ámbito de las relaciones internacionales efectúen análisis y sopesen previamente los posibles cursos de acción de los litigios que ventilen en esos tribunales. En el caso objeto de estudio, algunos juristas internacionalistas colombianos advirtieron, y aún debaten respecto a que el litigio pudo evitarse, sin embargo predominó más la posición política que no valoró adecuadamente los posibles escenarios ni la forma histórica en que la CIJ ha sentenciado.

Cavalier y Lozano (2005: 49) señalan que

«Colombia ha debido abstenerse de concurrir a esta instancia, puesto que no pude concurrir válidamente a un tribunal cuya sentencia no puede cumplirse».

Agregan que de acuerdo con el reglamento del CIJ, Colombia pudo en su momento haber rechazado la «invitación» de Nicaragua a participar en este proceso dando aplicación a lo señalado en el numeral 5 del artículo 38 del reglamento de la Corte que señala

"Cuando el demandante pretenda fundar la competencia de la Corte en un consentimiento todavía no dado o manifestado por el Estado contra quien se haga la solicitud, ésta última se transmitirá a ese Estado. No será, sin embargo, inscrita en el Registro General ni se efectuará ningún acto de procedimiento hasta tanto el Estado contra quien se haga la solicitud no haya aceptado la competencia de la Corte a los efectos del asunto de que se trate». 
En ese sentido, Colombia no debió haber aceptado la competencia de la $\mathrm{CIJ}^{3}$.

\section{LA TAREA DE LA CIJ SEGÚN}

\section{LAS FUENTES DEL DERECHO INTERNACIONAL}

Mediante el tratado Bárcenas Meneses-Esguerra de 1928, en adelante el tratado de 1928, y su protocolo de 1930, Colombia y Nicaragua establecieron sus límites en la zona del Caribe Occidental. Históricamente, Nicaragua había alegado la invalidez del mismo en virtud de la ocupación por Estados Unidos al momento de su celebración. Como se mencionó, cuando Colombia aceptó presentarse al juicio dio su aquiescencia anticipada frente a una futura decisión, en virtud de la cual podrías verse afectada la intangibilidad de las fronteras nacionales, sin mayores posibilidades de reconsideración por la CIJ si el resultado resultaba adverso a los intereses de Colombia, como efectivamente ocurrió.

Los representantes de Colombia debieron haber sido conscientes de que

La norma señala lo siguiente: «Cuando el demandante pretenda fundar la competencia de la Corte en un consentimiento todavía no dado o manifestado por el Estado contra quien se haga la solicitud, ésta última se transmitirá a ese Estado. No será, sin embargo, inscrita en el Registro General ni se efectuará ningún acto de procedimiento hasta tanto el Estado contra quien se haga la solicitud no haya aceptado la competencia de la Corte a los efectos del asunto de que se trate». pese a que la Constitución Política en su artículo 101 señala que los límites solo podrán modificarse en virtud de tratados aprobados por el Congreso, debidamente ratificados por el Presidente de la República, para la CIJ el derecho interno no es una fuente imperativa. Hoy el ejecutivo colombiano alega que la decisión es inaplicable, por esa y otras razones. Sin embargo, la resolución es vinculante y su cumplimento puede hacerse forzado a través de los organismos del sistema de las Naciones Unidas.

La Corte Constitucional colombiana (Sentencia C-400/98 y Sentencia C-1022/99) ha reconocido que los tratados de límites también forman parte del bloque de constitucionalidad puesto que conforme al artículo 102 de la Carta representan elementos constitutivos del territorio nacional, y por ende del propio Estado colombiano. En ese sentido, también formarían parte del mismo las interpretaciones y decisiones que sobre ellos hagan tribunales internacionales cuya jurisdicción haya sido reconocida por Colombia. En ese sentido, es el ordenamiento interno el que debe adaptarse al internacional y no a la inversa.

En lo que respecta a las fuentes propias del derecho internacional, el artículo 38 del estatuto de la CIJ consagra como tales las convenciones internacionales, la costumbre internacional, los principios generales de derecho reconocidos por las naciones civilizadas, las decisiones judiciales y las doctrinas de los publicistas de mayor competencia de las distintas naciones. Adicional- 
mente, la misma norma no restringe la facultad de la CIJ para decidir un litigio ex aequo et bono, si las partes así lo acuerdan. Se ha discutido si estas fuentes tienen un carácter enumerativo o taxativo y si existe una jerarquía de estricto seguimiento, frente a lo cual la doctrina mayoritaria se inclina por entender que la enunciación es abierta y la jerarquía depende de la existencia de las fuentes en cada caso concreto, pues una interpretación contraria impediría el desarrollo del derecho internacional.

En el caso en estudio, las partes daban por realizado que la CIJ iniciaría su tarea con base en el tratado de 1928, siguiendo las reglas de la Convención de Viena de 1969. Si bien es cierto la CIJ se refirió a este asunto, su labor no fue prolija, pues para ella este no era el único punto de análisis, que sí lo fue dentro de la pretensión inicial de Nicaragua. La justicia internacional obliga a los tribunales a señalar de forma pública la interpretación de los tratados en que basan sus fallos, así como determinar por qué no los aplican. Ese punto se agotó para la CIJ al fallar las excepciones preliminares en 2007 y en la primera parte de la sentencia de 2012.

Torres, Treves y Valticós (1999: 10) anotan que respecto de la formas de interpretación de la $\mathrm{CIJ}$ «los publicistas se agrupaban en escuelas interpretativas enfrentadas. Las textualistas chocaban con las subjetivistas y los partidarios de interpretaciones finalistas o teleológicas tanto con los textualistas como los subjetivistas». Sin embargo, hoy en día predomina la interpretación subjetivista y eso pone en vilo la predeterminación en la forma de actuar de la CIJ y la seguridad jurídica de los Estados partes en los instrumentos que la reconocen como juez natural para dirimir sus controversias.

Si bien la Convención de Viena de 1969 positivizó las reglas de interpretación de los tratados, actualmente se aplica un sistema dual que comprende estas y las pautas interpretativas propias de la CIJ, que no siempre coinciden en todos sus aspectos.Las primeras están consagradas en los artículos 31 a 33 de esta convención, que entró en vigencia en 1980 y comprenden la buena fe y la interpretación por contexto. Esta involucra elementos intrínsecos y extrínsecos e incluye la posibilidad de acudir a medios complementarios, en particular a los trabajos preparatorios del tratado y a las circunstancias de su celebración, para confirmar su sentido cuando sea ambiguo u oscuro; o cuando conduzca a un resultado manifiestamente absurdo o irrazonable.

Según Torres, Treves y Valticós (1999: 45), al analizar la jurisprudencia de la CIJ de 1970 a 1997 se observa una renuencia a aplicar estos principios, lo que revela desviaciones textualistas y rebrotes subjetivistas. Según los autores:

El sistema de Viena no autoriza a razonar mediante una serie de interpretaciones parciales sucesivas que se van acumulando o contraponiendo y que de esta forma condicionan apriorísticamente, se quiera o no, el resultado final de la interpretación jurídicamente relevante antes de la 
conclusión del proceso interpretativo correspondiente. El proceso interpretativo tiene que permanecer abierto hasta su conclusión, es decir hasta que se apliquen integralmente las reglas de interpretación codificadas al caso y se constate su interacción mutua en la determinación del sentido del tratado o de la disposición objeto de interpretación si se recurriese a un método integrador de este tipo, el grado de objetividad y predecibilidad de las interpretaciones judiciales internacionales aumentaría considerablemente y se ajustaría más a derecho.

Según Radbruch (1935) la tarea de la CIJ consistiría generalmente en ofrecer una razón final sobre lo pensado, «una mezcla indisoluble de elementos productivos y reproductivos, teóricos y prácticos, cognoscitivos y creativos, objetivos y subjetivos, científicos y supra científicos». Esta sería la interpretación finalista que se aparta de las reglas reconocidas y lleva a soluciones que aunque se tilden de equitativas producirán la sensación opuesta en la parte vencida en el juicio. La CIJ debió haber empezado por una interpretación filológica del tratado que tuviera en cuenta lo que dice. Al utilizar el método totalizante, dando una dinámica propia al orden de las fuentes del derecho internacional, quedó habilitada para seguir su propio camino hilando interpretaciones que dieron origen a razonamientos posteriores que pudieron alejarla de las expectativas comunes.

Cuando se analiza el resultado final de la delimitación y distribución geográfica de la zona, pareciera que la
CIJ hubiese fijado primero el resultado y posteriormente acomodado los medios a esos fines. Esto se sustenta en que antes de interpretar el caso debió armar el panorama fáctico a partir de las pruebas y después establecer las fuentes en un orden coherente. La CIJ combina tratados, jurisprudencia y derecho consuetudinario conforme al resultado que espera obtener.

$\mathrm{Al}$ omitir la CIJ el orden preestablecido la cadena interpretativa se va desviando hasta llegar a un resultado diferente. Es el caso de la aplicación de la Convención de las Naciones Unidas sobre el Derecho del Mar (CONVEMAR) de la que Colombia no es parte y Nicaragua sí, estos se hizo en el entendido de que ella refleja la costumbre internacional y existe regla jurisprudencial al respecto. Eso fue lo que ocurrió pues el resultado final fue un fallo que altera la administración del Caribe Occidental y pone en vilo los tratados establecidos con terceros Estados. Las partes ahora deberán entrar negociar un nuevo tratado en el que Nicaragua tiene una posición dominante y privilegiada otorgada por la sentencia en estudio.

\section{El desarRollo del CASo}

La CIJ inició su sentencia reseñando las pretensiones de las partes en los distintos momentos procesales, como la demanda, la réplica, la memoria y la audiencia oral. Posteriormente presentó las principales vicisitudes geográficas 
para de allí pasar a los aspectos de soberanía. En este último punto empezó su verdadera labor interpretativa deduciendo y fijando las reglas que sirvieron de soporte para fallar la controversia. Su tarea posterior se dividió en dos partes, en la primera de las cuales asignó soberanía a las formaciones marítimas, mientras que en la segunda trazó la fronter, a partir de los derechos derivados de ella.

En la primera parte invocó la regla jurídica que señala que «las islas por pequeñas que sean son susceptibles de apropiació (Qatar c. Bahréin, 2001), de la cual concluyó que las elevaciones de baja mar no podían ser apropiadas y que un Estado costero tiene soberanía sobre ellas en la medida en que se encuentran en su mar territorial y pueden tenerse en cuenta para medir el punto de inicio del mar territorial. Las partes estuvieron de acuerdo en la existencia $\mathrm{y}$ alcance de las reglas mencionadas, salvo en el caso de Quitasueño en el cual hubo diferencias respecto de si era o no isla. La cuestión probatoria permitió a las partes allegar dos informes contradictorios entre sí.

Colombia presentó el llamado informe Smith basado en el método norteamericano de la NASA para sostener que sí se trataba de una formación de alta mar, mientras que Nicaragua allegó uno basado en el método británico, que señalaba que no lo era. La CIJ desechó los informes como fundamento de una posible interpretación de autoridad y señaló que según su propia jurisprudencia (Caso Papeleras,
Argentina c.Uruguay, 2010) los méritos, la confiabilidad y la autoridad de los documentos presentados por las partes sirven para determinar los hechos relevantes y aplicar las reglas del derecho internacional. Finalmente, concluye que la formación llamada QS32 permanece por encima del mar en marea alta, a 0,7 metros.

Determinado lo anterior, la CIJ recuerda que en 2007, al decidir las excepciones previas presentadas por Colombia, determinó que el tratado de 1928 le asignó a este país la soberanía sobre el Archipiélago de San Andrés. Entonces, en el fallo del 2012 correspondía interpretar el alcance del tratado en cuanto a definir qué elementos componen el archipiélago, especialmente si las islas de Alburquerque, Bajo Nuevo, cayos de Este-Sudeste, Quitasueño, Roncador, Serrana y Serranilla le pertenecen. La CIJ omitió interpretar el tratado en extenso pues para definir la soberanía le otorgó mayor peso a fuentes subsidiarias como la costumbre, su propia jurisprudencia y los principios generales de derecho internacional.

Previamente las partes habían expuesto argumentos históricos, geográficos, administrativos, políticos, e incluso la literalidad del tratado. Con base en algunos de estos elementos, su interpretación comenzó por realizar una revisión causalista atendiendo al tenor literal de las disposiciones contractuales para encontrar la composición del archipiélago. Señaló que ni el tratado de 1928 ni el Protocolo de 1930 se 
pronunciaron al respecto y solo lo hizo frente al establecer un límite al este del archipiélago, en el meridiano 82.

La opinión individual del juez Abraham hace hincapié en que el tratado de 1928 era el título de soberanía sobre las islas en litigio, aunque la CIJ "podía escoger entre varias bases jurídicas invocadas ante ella para resolver el caso». La CIJ se equivocaba al sostener que interpretará qué integra el archipiélago de San Andrés y no hacerlo por falta de material probatorio. El juez Abraham añade que esta no es una razón que justifique tal omisión. Era una tarea difícil pero no imposible, además, la oscuridad del texto no podía ser excusa para no hacerlo.

En lo que corresponde al uti possidetis juris, su análisis se basa en lineamientos finalistas, de corte subjetivista, teniendo en cuenta su estructura de principio en términos dworkianos, lo que se torna problemático en la medida en que se centra en lo que se pruebe en el proceso, acompasado por la posición valorativa del juez. Pese a lo anterior, la CIJ termina desechando su aplicación sosteniendo que ninguno de los documentos sobre las órdenes coloniales anteriores a 1810 logró precisar un título constitutivo de soberanía sobre los elementos en disputa. En el caso Salvador/Honduras; Nicaragua interviniente (1992), la CIJ señaló como regla que respecto a este, el ius al que se refiere no es el derecho internacional sino el derecho constitucional o administrativo colonial español.
Al no llegarse a solución aplicando ese principio, la CIJ buscó una salida utilizando el principio de las efectividades, también de textura abierta. En el caso Nicaragua c. Honduras (2007) y en el reclamo de soberanía sobre Pulau Ligitan y Pulau Sipada (Indonesia/ Malasia, 2002) se dispuso que la fecha en que materializase una disputa es importante para señalar qué actos de soberanía se realizaron antes y después, siendo los primeros los realmente importantes, pues los segundos pudieron ocurrir para respaldar las pretensiones. La CIJ fijó como clave el 12 de junio de 1969, fecha en la cual Nicaragua respondió una nota diplomática de Colombia en el contexto de la concesión de explotación petrolera que hizo Nicaragua sobre el área de Quitasueño.

$\mathrm{Al}$ respecto, la $\mathrm{CIJ}$ ha señalado en sentencias como Nicaragua c. Honduras (2007) y Estatuto jurídico de Groenlandia Oriental (1993) una regla probatoria de los actos a títulos de soberanía que consiste en que los Estados pueden fijarlos a partir de una muestra relativa de evidencias de poderes del Estado, en términos de calidad y cantidad. La CIJ manifestó que los actos de administración pública y legislación, regulación de actividades económicas, obras públicas, medidas de aplicación de la ley, visitas navales y representación consular, entre otros, realizados por Colombia fueron públicos sin que Nicaragua protestara. También señaló, dando aplicación al principio res inter alios acta, que el posible reconocimiento de terceros Estados no era relevante. 
En su proceso de análisis, la CIJ distinguió entre elementos de reconocimiento y elementos de apoyo, lo cual deja entrever un proceso implícito de otorgamiento de peso a los aportes de las partes. Por ejemplo, al considerar los mapas como título, estos fueron descartados en virtud de la regla jurisprudencial de que tienen un valor muy limitado, tal como lo señaló en el caso Burkina Faso/República de Malí (1986). Finalmente, al sopesar concluye que Colombia sí tiene soberanía sobre las islas en disputa.

Superado el punto de la soberanía, y antes del ejercicio de delimitación, la CIJ analizó la admisibilidad de la nueva pretensión de Nicaragua para una delimitación de la plataforma continental extendiéndola más allá de 200 millas náuticas. En la demanda y en la memoria solicitó inicialmente que se delimitara una frontera única entre las áreas de plataforma continental y zona económica exclusiva de ambas partes a manera de una línea única entre las costas continentales. El cambio se basó en el artículo 76 de la CONVEMAR, que presuntamente le otorgaría el derecho a una plataforma extendida hasta el borde externo de su plataforma continental, sin considerar su extensión, dado que las plataformas continentales de las partes se yuxtaponen.

El cambio en las pretensiones de Nicaragua se justificaba a partir del fallo de excepciones preliminares de 2007, que lo llevó a alegar que la plataforma continental colombiana no se extiende más allá de las 200 millas y la nicaragüense sí. A raíz de ello planteó dos cuestiones problemáticas: la procedencia de la mutación en lo pedido y la aplicabilidad a Colombia de una regla convencional a la cual no se ha adherido, es decir a la CONVEMAR. Frente a lo primero la CIJ se remitió a su misma jurisprudencia(casos Nicaragua c. Honduras, 2007, y Guinea c. El Congo, 2010)para dejar sentado que este cambio, por sí mismo, no lo hace inadmisible puesto que lo decisivo es la conexión entre la pretensión inicial y la final.

Colombia alegó que Nicaragua cambió la pretensión y con ello la materia propia del caso. La opinión disidente del juez Owada señaló que esta situación no tiene precedente pues efectivamente hubo cambio en lo pedido, y que no se trató de un asunto exclusivamente de procedibilidad formal, puesto que sí influye en la equidad procesal del caso. La CIJ no debió haber estudiado la pretensión final sino realizar un análisis más detenido para determinar que efectivamente no se podía hacer un giro de esta naturaleza ya que de alguna manera desestabilizaba la línea de defensa que venía sosteniendo Colombia.

Frente a la aplicabilidad de la CONVEMAR, que fue suscrita por Nicaragua en el año 2000 y considerando que los tratados solo obligan a las partes, la CIJ concluyó que a Colombia se aplican por vía indirecta los artículo 74 y 83 (Delimitación de zona económica exclusiva y plataforma continental entre Estados con costas adyacentes o situadas frente a frente)en 
cuanto ese instrumento recoge la costumbre internacional, que sí es fuente vinculante en la materia y que además se refleja en sentencias de la CIJ y de otros tribunales.

Tal situación, que debió haberse analizado más a fondo, pues tal vez estas disposiciones no tengan en estricto sentido origen consuetudinario, haría variar la hermenéutica de las fuentes y de paso, los derechos de Colombia sobre el mar y la plataforma continental. En este debate, la CIJ debió prestar mayor atención al hecho de que Nicaragua ha sobrepasado el plazo de los diez años para enviar a la Comisión de Límites de la Plataforma Continental la información completa del trazado de su plataforma más allá de las 200 millas. Lo enviado fue insuficiente y preliminar y ocasionó que la línea final al este en el trazado de la CIJ no quedara plenamente todo definida, tal como lo señala el el juez ad-hoc Mensah. Sin embargo, la CIJ no acepta que el derecho se extienda más allá de las 200 millas y desecha lo pretendido por Nicaragua. En septiembre de 2013, Nicaragua anunció la interposición de una nueva demanda contra Colombia por considerar que su plataforma se prolonga hasta puntos cercanos a las costas colombianas ante la indefinición de ese límite en la sentencia.

A partir de ese momento la CIJ empieza la segunda etapa de su trabajo, que consiste en el trazado de la frontera marítima, advirtiendo que en ese ejercicio no excederá la jurisdicción conferida por las partes, centrada en el trazado de una frontera marítima única. Tal advertencia resulta inútil puesto que el fallo se produjo ultra $y$ extra petita. En su labor hermenéutica y antes de examinar los argumentos de las partes y utilizando métodos geométricos y cartográficos, la CIJ fija las costas relevantes para señalar el contexto general, las áreas que se superponen y si existe desproporción en la longitud de cada costa (véase Rumania c. Ucrania, 2009). Señala que la costa continental nicaragüense tiene una extensión de 531 kilómetros mientras que la de Colombia es de 65 kilómetros, dándose una relación de 1 a 8,2 en favor de Nicaragua. Excluye a Serranilla y Bajo Nuevo en razón de que estas zonas pertenecen a un área de administración común que Colombia y Jamaica dejaron sin limitar, donde hay derechos de terceros Estados.

Con lo anterior se procede a definir la zona marítima relevante que es donde los derechos de las partes se superponen. Este concepto, junto con el de costa relevante es indeterminado y le otorgan un grado de libertad en materia interpretativa para definir en cada caso su contenido ante la ausencia de reglas claras (Rumania c. Ucrania, 2009, y Dinamarca c. Noruega, 1993). El empleo de este tipo de categorías hace caer en interpretaciones que pretenden la equidad, por lo que la CIJ insiste en que la delimitación no tiene por objeto repartir en partes iguales ni proporcionales y fija un área de $209.280 \mathrm{~km}$., tomando en cuenta al norte la delimitación establecida en la 
sentencia de 2007 entre Honduras y Nicaragua y al sur posibles derechos de terceros Estados, como Costa Rica y Panamá.

La juez Xue señala que posiblemente se afecte a terceros Estados, especialmente Costa Rica y Panamá, e incluso supone que la CIJ pudo haber excedido la jurisdicción otorgada. Según ella, la línea trazada en el sur pudo haber invalidado los tratados de Colombia con esos países. Sobre este último punto están de acuerdo el juez ad-hoc Cot y el juez Mensah. En el mismo sentido, la jueza Donoghue critica que, de acuerdo con el reglamento de la CIJ, Costa Rica y Honduras tenían la calidad necesaria para intervenir en el proceso, pero se les impidió hacerlo.

El cuadro 1 señala la situación de los derechos generados por los accidentes marítimos que están dentro del área relevante y el fundamento jurídico utilizado por la CIJ al respecto.

Cuadro 1- Consideraciones de la CIJ respecto de los derechos generados por los accidentes maritimos

\begin{tabular}{|l|l|l|}
\hline Accidente marítimo & Derechos generados & $\begin{array}{l}\text { Fundamento jurídico } \\
\text { empleado por la CIJ }\end{array}$ \\
\hline $\begin{array}{l}\text { San Andrés, Provi- } \\
\text { dencia y Santa } \\
\text { Catalina }\end{array}$ & $\begin{array}{l}\text { A mar territorial, zona económica } \\
\text { exclusiva y plataforma continen- } \\
\text { tal. Este derecho tiene la capacid- } \\
\text { ad de extenderse hasta 200 millas } \\
\text { náuticas en cada dirección. }\end{array}$ & $\begin{array}{l}\text { Costumbre internacio- } \\
\text { nal y CONVEMAR }\end{array}$ \\
\hline $\begin{array}{l}\text { Serranilla y Bajo } \\
\text { Nuevo }\end{array}$ & $\begin{array}{l}\text { Quedan fuera del área relevante } \\
\text { yen consecuencia la CIJ no debe } \\
\text { pronunciarse sobre el proced- } \\
\text { imiento para determinar el al- } \\
\text { cance de sus derechos marítimos. }\end{array}$ & $\begin{array}{l}\text { Tratado entre Colom- } \\
\text { bia y Jamaica y senten- } \\
\text { cia Nicaragua c. Hon- } \\
\text { duras, 2007. }\end{array}$ \\
\hline $\begin{array}{l}\text { Alburquerque, cay- } \\
\text { os del Este-sureste, } \\
\text { Roncador y Serrana }\end{array}$ & $\begin{array}{l}\text { Tiene derecho a 12 millas náu- } \\
\text { ticas, pero sus derechos pueden } \\
\text { quedar inmersos dentro de los } \\
\text { derechos de San Andrés, Provi- } \\
\text { dencia y Santa Catalina. Se dese- } \\
\text { cha la teoría de Nicaragua del } \\
\text { derecho a 3 millas náuticas. }\end{array}$ & $\begin{array}{l}\text { Costumbre internacio- } \\
\text { nal y CONVEMAR y } \\
\text { precedentes jurispru- } \\
\text { denciales }(v . \text { gr.Qatar c. } \\
\text { Bahréin, 2001; Nicara- } \\
\text { gua c. Honduras, 2007; } \\
\text { Bangladesh c. Myan- } \\
\text { mar, 2012) }\end{array}$ \\
\hline Quitasueño & $\begin{array}{l}\text { La única formación relevante es } \\
\text { QS32, pero como no es apto para } \\
\text { la habitación humana no gen- } \\
\text { era derecho a plataforma o zona } \\
\text { económica exclusiva. }\end{array}$ & $\begin{array}{l}\text { Costumbre internacio- } \\
\text { nal y CONVEMAR } \\
\text { (art. 13) }\end{array}$ \\
\hline
\end{tabular}

Fuente: Elaboración propia 
Mediante su jurisprudencia (Jamahiriya Libia c. Malta 1985 y Rumania c. Ucrania, 2009) la CIJ ha diseñado un método de delimitación cuando exista superposición entre las plataformas continentales y los derechos de la zona económica exclusiva. De acuerdo con él se recorren tres etapas que comprenden el trazo geométrico de una línea media entre costas opuestas, seguido de la consideración de circunstancias pertinentes que puedan dar lugar a ajustes a la línea provisional y la aplicación final de un test de desproporcionalidad. La CIJ advirtió de forma preliminar que el método no debía aplicarse de manera mecánica por lo cual podía realizar cambios, como ya lo había hecho en el pasado (Nicaragua c. Honduras, 2007) apartándose de sus precedentes, especialmente debido a condiciones particulares como la disparidad de las costas y a que la mayor parte del área relevante se encuentra al este. Es decir, aplicaría la equidad como fundamento de su decisión.

Pese a que Nicaragua planteó que la CIJ podía prescindir del método e iniciar enclavando las islas, el tribunal rechazó la solicitud. En la primera etapa la CIJ señaló los puntos de base en cada costa relevante en función de las condiciones geográficas (véase Rumania c. Ucrania, 2009), descartando puntos muy pequeños distorsionantes de la geografía ubicados en Quitasueños, Serrana y Roncador. Posteriormente estableció una línea media provisional surgida al enfrentar las proyecciones de los puntos de base hasta llegar a un resultado calificó de equitativo, prestando atención a argumentos de las partes respecto a la disparidad de las costas y un posible efecto de amputación. Con ello la CIJ otorgó un valor unitario a los puntos de base colombianos y uno triple a cada uno de los puntos de base nicaragüenses, generando lo que denomina una línea ponderada simplificada.

La CIJ justifica de manera escueta su trabajo aseverando por ejemplo que «esta línea no llevaría a un resultado equitativo si penetra en los sectores...». Al norte recorta el punto para que el trazado pase en línea recta a $12 \mathrm{mi}$ llas náuticas de Rocador. Al sur hace algo similar para que pueda armarse un arco trazado a 12 millas náuticas de los cayos y de ahí en adelante va definiendo una serie de arcos y puntos a su acomodo, buscando un resultado presuntamente equitativo y dejando a Quitasueño y Serrana aislados y enclavados con sus 12 millas, al igual que Serranilla y Bajo Nuevo, deformando la continuidad geográfica y la comunicabilidad entre las islas. Finalmente, la CIJ aplica la prueba de desproporcionalidad teniendo en cuenta el conjunto de circunstancias y el hecho de que exista o no una desproporción marcada que requiera nuevos ajustes.

La CIJ advierte que no se trata de establecer una proporcionalidad en sentido estricto, que lleve a evaluar la correspondencia entre longitudes costeras y que solo persigue que no exista una desproporción marcada. Señala que el área quedó dividida a razón de 1 a 3,44 en favor de Nicaragua, a pesar de 
que las costas tienen una proporcionalidad de 1 a 8,2. La tarea concluye allí al no existir razones para aplicar ajustes adicionales, quedando sin definirse con exactitud el límite al este, como ya se mencionó. El resultado final puede observarse en el mapa 1. más utilizando varios métodos e incluso se atreve a proponer lo que para ella hubiese podido ser una alternativa de delimitación más directa y evitar cambios inusuales de metodología. En ese sentido, la juez Xue señala que el método no puede ser predeterminado pues

Mapa 1- Delimitación final

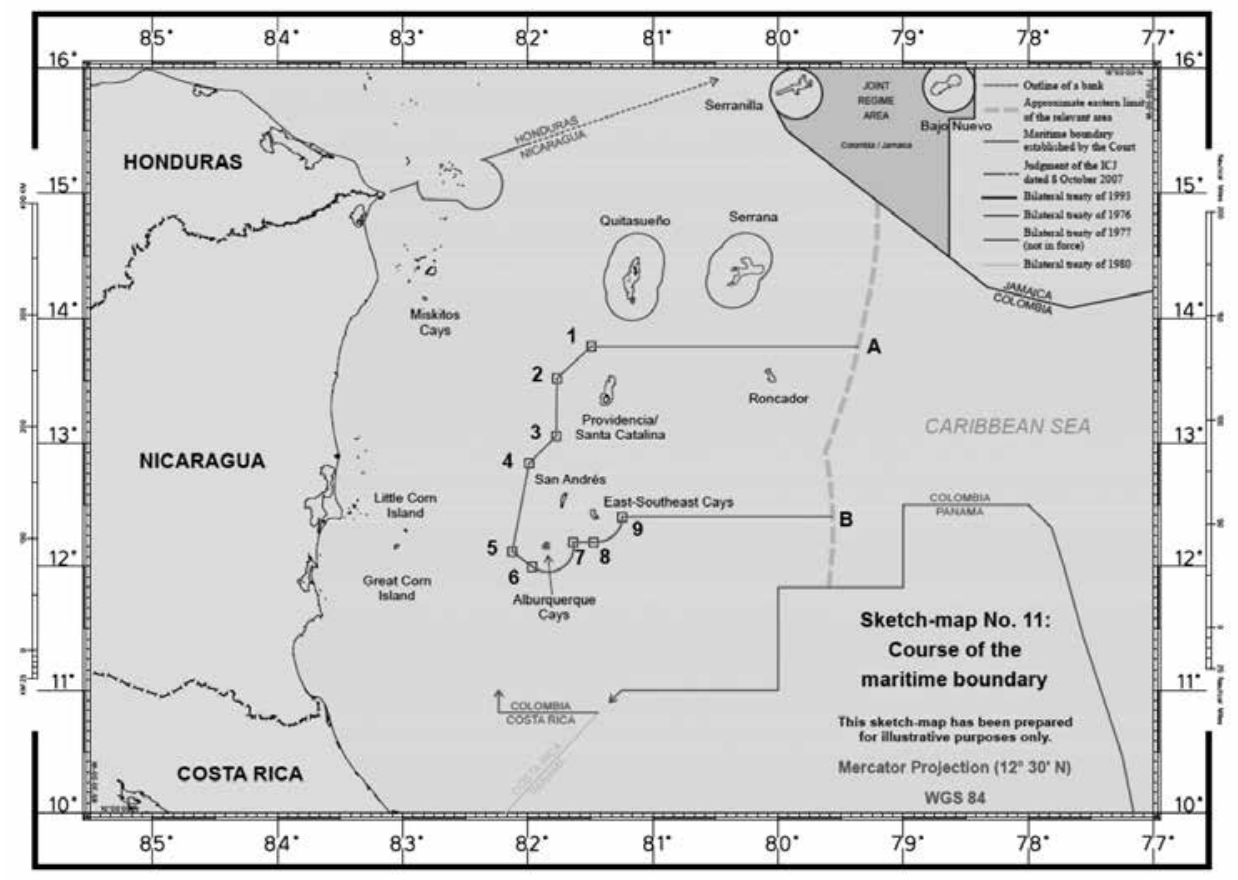

Fuente: Croquis 11, tomado directamente de la sentencia

Respecto del método, el juez Keith reconoce que no se puede desconocer el principio de legalidad. La CIJ reconoció que aunque existe un método para delimitar había varios caminos para hacerlo y en el caso actual la geografía no favorecía una solución fácil. Se usó la equidad tratando de evitar el efecto cutoff, pero la CIJ hubiese podido llegar a depende en cada caso de condiciones geográficas y podría haberse llegado al resultado aplicando otro método.

\section{Conclusión}

En la solución del caso la CIJ caso utilizó diferentes métodos, por lo que 
puede afirmarse que su hermenéutica fue totalizante. Las interpretaciones textualistas aparecen en menor medida, predominando las finalistas, en las que cumplió una función importante la equidad. Al revisar la forma de razonar de la CIJ en la sentencia se confirman las críticas de que ha sido objeto permanentemente su labor, en el sentido de que pese a que en el ámbito del derecho internacional la enumeración de las fuentes da amplio margen de discrecionalidad para utilizar la equidad como base de su trabajo puede aplicar una ordenación propia para cada caso, eligiendo aquellas fuentes que se acomoden a un resultado final que podría haberse fijado ex ante y catalogársela como subjetivista, sobre todo por la parte vencida, como lo fue Colombia.

En este caso a Nicaragua le reasignaron aproximadamente 75 mil kilómetros que Colombia consideraba desde hacía muchos años que le pertenecían, lo que ha dado lugar a un inconformismo generalizado, sobre todo en los sectores políticos que quieren obtener ventajas de la popularidad electoral ante la ciudadanía, que desconoce muchos detalles del asunto. El gran error no radica en la decisión, puesto que la $\mathrm{CIJ}$ es un tribunal colegiado que hace interpretaciones ajustadas dentro del ámbito de lo que ha ido construyendo a través de su propia jurisprudencia como justo, a partir de asuntos que le son sometidos por las partes de común acuerdo.

Colombia aceptó que la solución de la controversia se entregara a la juris- dicción y competencia de la CIJ, pese a la existencia de un tratado vigente desde 1928 y a sabiendas de que podría obtenerse un resultado totalmente adverso. Colombia ahora reclama el derecho a la subversión, es decir, a no cumplir el fallo por ser inconveniente a sus intereses y violatorio de su Constitución Política. Este tipo de anuncios es muy cuestionable desde el punto de vista ético y político pues el mensaje que transmite la institucionalidad colombiana a sus ciudadanos es que solo deben acatarse las decisiones judiciales que le favorecen.

Aunque el sistema de las Naciones Unidas tiene medios para obtener la ejecución forzada de la sentencia ante un posible incumplimiento por parte de Colombia, el gobierno nacional colombiano ha sostenido que el fallo no puede ejecutarse porque es contrario a la Constitución, situación que podría no ser totalmente cierta, ya que así como los tratados fronterizos forman parte del bloque de constitucionalidad, según lo ha dicho la propia Corte Constitucional, a nuestro juicio puede entenderse que las sentencias declarativas e interpretativas de ellos, dictadas por una jurisdicción internacional aceptada, también le obligan y deben armonizarse con las normas constitucionales para eliminar cualquier asomo de imposibilidad jurídica generada a la luz del derecho interno.

Colombia debe respetar el principio de ius cogens. No puede por una parte vanagloriarse de ser un Estado social de derecho en el ámbito interno y al mismo 
desconocer el orden internacional porque estaría violando sus propias bases y ello constituiría una gran contradicción en materia de política exterior. Para un Estado, del que hace un siglo se escindió Panamá, sería doloroso perder hoy parte de su territorio, pero se trata de circunstancias diferentes. Por tanto, la salida debe tener asidero en la diplomacia y el diálogo a fin de lograr una administración pacífica y conjunta del Caribe occidental con todos sus vecinos.

Las advertencias consecuencialistas del juez ad-hoc Cot, que prevé que la aplicación del fallo sin acuerdo previo entre las partes puede conducir a un desastre ecológico de mayores proporciones y dejar un importante corredor marítimo para el narcotráfico, son acertadas. El Caribe occidental es una zona marítima compleja y sensible que requiere consenso no solo en la delimitación sino entre otras cosas respecto a la adecuada administración ambiental del medio marino, de los recursos pesqueros, y de la investigación científica.

En esa posición rebelde Colombia ha dictado una serie de actos administrativos que crean una zona contigua integral, lo cual no solo carece de significación para el derecho internacional sino que atenta contra la cortesía internacional. Lo que debe hacer Colombia, y está en mora de hacer, es establecer una mesa de diálogo para llegar a un acuerdo válido con Nicaragua, siempre que ese Estado sea aquiescente, ya que la sentencia de la CIJ le otorga directamente una posición de ventaja.
Otra medida adoptada por Colombia ha sido denunciar el Pacto de Bogotá y demandar ante la Corte Constitucional la inconstitucionalidad de la ley aprobatoria de esta convención a fin de desvincularse de la jurisdicción de la $\mathrm{CIJ}$, asunto que es irrelevante frente un fallo de obligatorio cumplimiento. No obstante, es preocupante que Nicaragua haya anunciado una nueva demanda para definir las coordenadas precisas de los puntos A y B o límites orientales de su plataforma, reclamando mayores áreas marítimas más allá de las 200 millas náuticas, asunto que está sujeto a las recomendaciones de la Comisión de Límites de la Plataforma Continental. En ese nuevo escenario, la diplomacia, la concertación, la cortesía, el estudio juicioso y la cautela deber los principios rectores en el manejo de las relaciones internacionales. Si Colombia quiere salir de esta encrucijada no debe actuar con la soberbia y la arrogancia del pasado.

\section{Bibliografía}

Cavalier, Germán y Alberto Lozano (2005), El ataque de Nicaragua a la soberanía colombiana, Punto vital: ¿Controversia internacional o violación al ius cogens? Bgotá, Colección Relaciones Internacionales: Universidad Jorge Tadeo Lozano, pp.25-88.

Dueñas, Oscar José (2007), Lecciones de hermenéutica jurídica, $4^{a}$. edición, Bogotá: Ediciones Universidad del Rosario, pp.30-49.

Galán, Diego Ricardo (2010), «El Concepto de soberanía en el diferendo territorial y marítimo entre Nicaragua y Colombia: un desafío a nuestra ignorancia sobre la 
geografía nacional», Revista Análisis Internacional, número 1,pp. 141-153.

Grossman, Claudio (2011), «Nuevos paradigmas en la formación jurídica en Estados Unidos», en González,Joaquín y Eloy García (eds.),La crisis las fuentes del derecho en la globalización, Bogotá: Diké, pp. $89-110$

Pagliari, Arturo Santiago (2004), «El derecho internacional público. Funciones, fuentes, cumplimiento y la voluntad de los estados", Anuario Mexicano de Derecho Internacional,vol. IV, pp.450-462.

Rabbi-Baldi, Renato (2013), Teoría del derecho, $3^{\mathrm{a}}$. edición, Buenos Aires: Ábaco, pp. 291-358.

Radbruch, Gustav (1935), Relativismo y derecho, traducción de Villar Borda, Luis (2009), Serie Monografías jurídicas, Bogotá:Temis. pp. 10-72.

Torres, Santiago, Tulio Treves, y Nicolás Valticós (1999): Tres estudios sobre la Corte Internacional de Justicia, Madrid: Instituto de Estudios Internacionales y Europeos «Francisco de Vitoria» de la Universidad Carlos III de Madrid, pp.11-52.

\section{Jurisprudencia consultada}

Corte Constitucional de Colombia, Sentencia T-319 de 2012, Magistrado Ponente: Luis
Ernesto Vargas Silva. Bogotá, 3 de mayo de 2012.

Corte Constitucional de Colombia, Sentencia C-296 de 2012, Magistrado Ponente: Juan Carlos Henao Pérez, Bogotá, 18 de abril de 2012.

Corte Constitucional de Colombia, Sentencia C-820 de 2006. Magistrado Ponente: Marco Gerardo Monroy Cabra. Bogotá, 4 de octubre de 2006.

Corte Constitucional de Colombia,Sentencia C-478 de 2003. Magistrado Ponente: Clara Inés Vargas Hernández. Bogotá, 10 de junio de 2003.

Corte Constitucional de Colombia,Sentencia C-1022 de 1999. Magistrado Ponente:Alejandro Martínez Caballero. Bogotá, 16 de diciembre de 1999.

Corte Constitucional de Colombia,Sentencia C-400 de 1998. Magistrado Ponente:Alejandro Martínez Caballero. Bogotá, 10 de agosto de 1998.

Corte Constitucional de Colombia,Sentencia C-461 de 2013. Magistrado Ponente: Nilson Pinilla Pinilla. Bogotá, 17 de julio de 2013.

International Court of Justice, Judgment of 19 November 2012 - Territorial and maritime dispute (Nicaragua v. Colombia). Recuperado el 12 de agosto de 2013 de http:// www.icj-cij.org/docket/files/124/17164. pdf 